\title{
FEDERALISMO, DESCENTRALIZAÇÃO E MUNICIPALIZAÇÃO: DESAFIOS DAS POLÍTICAS PÚBLICAS PARA A GESTÃO EDUCACIONAL
}

\author{
M. F. S. MELO, S. B. S. FERNANDES, F. F. A. OLIVEIRA
}

Universidade do Estado do Rio Grande do Norte (UERN)

fatima.melo@live.com

\section{RESUMO:}

O trabalho propõe uma discussão sobre o federalismo, o processo de descentralização e a municipalização, enfatizando as políticas públicas que norteiam a gestão educacional. Objetiva identificar as mudanças desencadeadas na gestão da educação a partir do processo de municipalização e refletir sobre os desafios enfrentados por essa nova organização política. Para este estudo, realizamos uma revisão bibliográfica baseada em autores como Barroso (2002) e Azevedo (1997) que discorrem sobre políticas públicas e a gestão da educação básica; Akkari (2011) que reflete sobre a internacionalização das políticas educacionais e os seus desafios; Araújo (2010) que discute sobre a relação existente entre federalismo e municipalização, historicizando esse processo no Brasil. E por fim, a Constituição Federal de 1988 e a Lei de Diretrizes e Bases da Educação - LDB 9394/96 que regulamentam a educação brasileira. Esta investigação nos possibilitou refletir sobre o processo de municipalização no Brasil. Dessa forma, foi possível inferir que o processo de municipalização trouxe desafios, mas também ganhos para a gestão da educação, uma vez que a discussão surge com base nos princípios de autonomia, de democracia e de descentralização no cotidiano escolar, bem como a oportunidade dos municípios instituírem suas próprias políticas educacionais, seus Sistemas Municipais de Ensino-SME.

\section{FEDERALISM, DECENTRALIZATION AND MUNICIPALIZATION: CHALLENGES OF PUBLIC POLICIES FOR EDUCATIONAL MANAGEMENT}

\section{ABSTRACT:}

The paper offers a discussion about federalism, decentralization and municipalization, stressing the public policies that govern educational management. It aims both to identify the changes that have taken place in the educational management through the process of municipalization and to deliberate the challenges faced by this new political organization. With these intents, a literature review was carried out based on authors such as Barroso (2002) and Azevedo (1997) who investigate public policies and the management of basic education; Akkari (2011) who discusses about the internationalization of educational policies and their challenges; and Araújo (2010) who argues the relationship between federalism and
\end{abstract}

municipalization, narrating the history of this process in Brazil. Finally, the Federal Constitution of 1988 and the Law of Directives and Bases of National Education - LDB 9394/96 that regulate Brazilian education were also taken into consideration. This research allowed the appraisal of the process of municipalization in Brazil. Consequently, it is inferred that the municipalization process resulted in challenges and gains to the educational management as the discussion arises based on the principles of autonomy, democracy and decentralization in school daily life. Furthermore, this process provides the municipalities the opportunity to establish their own educational policies and their Municipal Teaching Systems-SME.

KEYWORDS: Policies; Federalism; Decentralization; Municipalization; Educational Management. 


\section{INTRODUÇÃO}

Este artigo resulta dos estudos e discussões realizados na disciplina "Gestão Educacional em Contextos Locais", ministrada no Programa de Pós-graduação em Educação (POSEDUC), da Universidade do Estado do Rio Grande do Norte (UERN), na linha de pesquisa "Políticas e Gestão da Educação".

O trabalho propõe uma discussão sobre o federalismo, o processo de descentralização e a municipalização, enfatizando as políticas públicas que norteiam a gestão educacional. A escolha por essa discussão adveio pelo interesse de querermos perceber as possíveis aberturas que as políticas públicas proporcionaram para o processo de municipalização da gestão educacional e suas mudanças ocasionadas pela descentralização dos entes federativos.

Assim, o objetivo deste artigo consiste em identificar as mudanças desencadeadas na gestão da educação a partir do processo de municipalização e refletir sobre os desafios enfrentados por essa nova organização política. Com isso, pretende reafirmar sua relevância para compreender a organização educacional brasileira, as responsabilidades de cada ente federado, percebendo as influências das políticas para a gestão da educação.

Para este estudo realizamos uma revisão bibliográfica baseada em autores como: Barroso (2002) e Azevedo (1997) que discorrem sobre políticas públicas e a gestão da educação básica; Akkari (2011) que reflete sobre a internacionalização das políticas educacionais e os seus desafios; Araújo (2010) que discute sobre a relação existente entre federalismo e municipalização, historicizando esse processo no Brasil. E por fim, a análise documental: a Constituição Federal de 1988 e a Lei de Diretrizes e Bases da Educação - LDB 9394/96, que regulamentam a educação brasileira.

Compreendemos que a discussão acerca dessa temática se faz pertinente, uma vez que percebemos, nas leituras e nas discussões coletivas em sala de aula, a necessidade de refletir sobre os desafios que a gestão educacional municipal enfrenta diante do processo de descentralização, provindo pelas políticas públicas.

Procuramos entender sobre o processo de municipalização e a influência das políticas públicas na gestão da educação sobre a ótica de autores nomeados que discutem aspectos fundamentais sobre esse estudo. Assim, contribuímos para a ampliação do debate sobre as políticas públicas educacionais no campo científico, promovendo questionamentos sobre a temática e desenvolvimento de novas pesquisas.

Dessa forma, o presente trabalho está estruturado em dois momentos: primeiro, realizamos uma discussão sobre as mudanças no contexto histórico do federalismo, da descentralização e da municipalização, destacando a influência das políticas públicas nesse processo. Em segundo, abordamos os resultados e discussões sobre a municipalização e os desafios enfrentados pela gestão educacional. 


\section{REFERENCIAL TEÓRICO}

2.1 Federalismo, descentralização e municipalização: influências das políticas públicas educacionais.

O federalismo é composto por elementos essenciais, maior democracia e maior descentralização, como toda federação. Reportamos ao Dicionário de Políticas ${ }^{1}$ para entender o que se compreende por federação, este "é um produto político-jurídico em que determinadas regras são estabelecidas dentro da existência de uma Nação" (Andrade, 2012, p. 206).

No Brasil, o federalismo surgiu como alternativa para a centralização política e administrativa do período colonial e imperial. Após a Proclamação da República, a base da organização federativa, federalismo, deu lugar a um momento de descentralização política caracterizado pela abertura para os estados brasileiros na agenda política, e os municípios tiveram sua autonomia subordinada (Araújo, 2010). Assim, o que temos é uma nação federativa, em que cada estado possui autonomia política para agir em acordos e tratados com a federação.

A teoria tradicional base do federalismo é que os municípios integram a federação, mas não são entes federados. Com a Revolução Constitucionalista de 1932 houve conflitos em torno da federação. O intervencionismo estatal cresce como tendência no cenário político e institucional, dando lugar para o "municipalismo" se configurar como uma nova expressão de demandas por autonomia local (Araújo, 2010).

A conquista de repartição dos recursos e competências para o município antecede a Constituição Federal de 1988. Nesse sentido, Araújo (2010) afirma que o "municipalismo" ganha nitidez com o movimento que conseguiu assegurar a Carta de 1946 que prescrevia competências para o município como auxílios de renda. Esses resultados foram alcançados pela campanha dos municipalistas liderada por Rafael Xavier que buscava autonomia para os municípios. Essa campanha corroborou para a criação da Associação Brasileira dos Municípios (ABM) que lutava contras as incoerências de não se reconhecer a autonomia do local e do modelo dual (União e Estados) da nossa federação, lutando pela conquista de uma tripla soberania para reconhecer os municípios como ente da federação.

No Regime Militar, o movimento é silenciado, mas, com o período de redemocratização do país, a campanha dos municipalistas retoma com vigor, consumando formalmente o município como ente federado na promulgação da Constituição Federal de 1988. Podemos conferir o texto expresso nos artigos 10 e $18^{\circ}$ que legitimam:

\footnotetext{
${ }^{1}$ Dicionário de Política Pública no Brasil construído e divulgado pela Faculdade de Política Pública da Universidade do Estado de Minas Gerais (UEMG). Publicado em 2012 (online) no site <http://www.ebc.com.br/cidadania/2013/02/primeiro-dicionario-sobre-politicas-publicas-no-brasil>, pelos organizadores: Carmem Lúcia de Freitas Castro, Cynthia Rúzia Braga Gontijo e Antônio Eduardo de Noronha Gontijo Amantile.
} 
Art. 1ㅇ - A República Federativa do Brasil, formada pela união indissolúvel dos Estados e Municípios e do Distrito Federal, constitui-se em Estado Democrático de Direito e tem como fundamentos.

Art. 18 - A organização político-administrativa da República Federativa do Brasil compreende a União, os Estados, o Distrito Federal e os Municípios, todos autônomos, nos termos desta Constituição (Brasil, 1988).

A Constituição Federal de 1988 atende a reivindicação dos municipalistas e realça a conquista da autonomia dos municípios, considerando-os como ente federado. A posição que os municípios ocupam com a atual Constituição brasileira é impar se comparada a outras realidades federativas do mundo; temos como exemplo os Estados Unidos que é um país desenvolvido e apenas consideram os estados. Já no Brasil, os estados e municípios possuem igualdade e autonomia. Assim, "o município possui o regime de autonomia administrativa descentralizada, razão pela qual o seu governo e direção refletem a vontade de seus habitantes, os municípios, tendo por finalidade o atendimento dos objetivos locais" (Batista, 2012, p. 339).

É preciso esclarecer o que estamos compreendendo por descentralização, e para nos ajudar a entender buscamos inicialmente no dicionário de políticas públicas, que compreende a descentralização como um processo pelo qual os governos centrais "transferem ou compartilham o poder e a autoridade com os governos estaduais ou municipais, dando-lhes autonomia de gestão" (Espinosa, 2012, p. 117). As relações estabelecidas entre os organismos (ente federados) são relações de caráter horizontal e não verticalizada.

No Brasil, o conceito de descentralização utilizado supõe que sua implementação promova maior autonomia aos governos locais, uma vez que é concebido como:

[...] processo político que resulta em transferência orgânica e organizada e/ou conquista de autonomia fiscal e de gestão de políticas e autonomia em termos de poder decisório, sendo diferente, portanto, da mera delegação de funções administrativas (Filipim e Abruccio, 2010, p. 217).

No entanto, o que se percebe é que esse processo não tem se configurado na realidade municipal, pois o repasse de responsabilidades para os municípios podem se configurar novas formas de dominação e clientelismo pelos Estados e a própria União. Como se percebe nos resultados dos estudos de Filipim e Abruccio (2010), realizado no estado de Santa Catarina, constatam que a descentralização, ao contrário do que se espera, pode ser usada como mecanismo de concentração de poder. Isso porque, por um lado, a atuação do governo catarinense é propagada como maneira de se aproximar do cidadão, por outro, se construiu uma estratégia político-partidária de consolidação no poder da atual dominante no Estado.

Descentralizar não é desconcentrar o poder em partes, permanecendo o mesmo domínio de um partido, ou coligação política tomando as decisões político-administrativas dos municípios. A descentralização é levada para a educação pela intervenção da Lei de Diretrizes e Bases da Educação - LDB no 9394/96 que será esboçada aqui. Anísio Teixeira, participante do Manifesto dos pioneiros da Educação de 1932, um grande incentivador e defensor da municipalização do ensino, alertava para o fato de que o governo central deveria definir apenas as normas gerais da 
educação, os currículos, os métodos, as práticas didáticas e todas as questões de ordem política e didático pedagógica.

O problema é que essa descentralização proclamada está contaminada de idealismo, pois desconsidera as condições objetivas dos municípios e os aspectos históricos e culturais nas propostas educacionais. Uma vez que estas propostas são pensadas e elencadas pela União para todo o território brasileiro, muitas vezes desconsidera as realidades locais. Permite pensar a descentralização para a gestão municipal, inclusive na área educacional. É mister a busca de descentralizar a gestão educacional, quando compreendida como um processo de mobilizar a capacidade criativa e autonomia dos cidadãos em participar da formulação das suas próprias políticas, possibilita a administração dos serviços sociais, neste caso a educação (Castro e Lauande, 2009).

O processo de municipalização do ensino se intensifica com o movimento de reforma do Estado no século XX, mais precisamente na década de 1990, com o ajuste fiscal, a mudança e inovações no mercado, buscando o crescimento econômico, ampliando as políticas sociais e o relacionamento entre as esferas estadual, municipal e federal. Aqui se fortalece a municipalização do ensino quando se constrói uma nova regulação estatal, que não tem como objetivo centralizar as decisões no Estado-Nação, mas compartilhar e descentralizar o poder com as outras esferas, um processo de busca da redemocratização do país.

Com a nova ação do Estado, o conceito de descentralização é ressignificado, em que a ação autônoma dos sujeitos em busca de compartilharem do processo de decisão das políticas é substituída pela concepção de que a instância local executa e apenas um grupo seleto participa, deliberando o planejamento a ser executado (Andrade, 2012). Assim, a descentralização é apenas pertencente a um grupo seleto e os demais executam ou praticam os ditames estabelecidos, ou seja, uma centralização de decisões nas mãos de poucos e uma socialização para a maioria.

A municipalização do ensino trouxe desafios para a gestão local. Com a promulgação da LBD 9394/96 coube ao município a responsabilidade de ofertar educação. O Art. 11 estabelece as incumbências dos municípios para a educação:

\footnotetext{
Art. 11. Os Municípios incumbir-se-ão de:

I - organizar, manter e desenvolver os órgãos e instituições oficiais dos seus sistemas de ensino, integrando-os às políticas e planos educacionais da União e dos Estados;

II - exercer ação redistributiva em relação às suas escolas;

III - baixar normas complementares para o seu sistema de ensino;

IV - autorizar, credenciar e supervisionar os estabelecimentos do seu sistema de ensino;

$\checkmark$ - oferecer a educação infantil em creches e pré-escolas, e, com prioridade, o ensino fundamental, permitida a atuação em outros níveis de ensino somente quando estiverem atendidas plenamente as necessidades de sua área de competência e com recursos acima dos percentuais mínimos vinculados pela Constituição Federal à manutenção e desenvolvimento do ensino.

Parágrafo único. Os Municípios poderão optar, ainda, por se integrar ao sistema estadual de ensino ou compor com ele um sistema único de educação básica (Brasil, 1996).
}

Podemos perceber que recaiu sobre os municípios a incumbência e responsabilidade de organizar seu sistema de ensino. A sistematização da gestão da educação daquela localidade. 
Além disso, organizar a oferta da educação infantil para as crianças e o ensino fundamental, surgindo desafios de estrutura física especializada, capacitação profissional e recursos financeiros. No entanto, a União para ajudar aos municípios e Estados, criou propostas de políticas educacionais que legitimam os programas federais para auxílio financeiro, desenvolvendo um regime de colaboração.

Quanto ao regime de colaboração, a LBD 9394/96 destaca que:

Art. 8 A União, os Estados, o Distrito Federal e os Municípios organizarão, em regime de colaboração, os respectivos sistemas de ensino. § 1으 Caberá à União a coordenação da política nacional de educação, articulando os diferentes níveis e sistemas e exercendo função normativa, redistributiva e supletiva em relação às demais instâncias educacionais. $\S 2$ 응 Os sistemas de ensino terão liberdade de organização nos termos desta Lei (Brasil, 1996).

A partir da interpretação desse artigo, podemos inferir que é recomendado que, para a organização dos sistemas de ensino, os entes federados devem se articular em regime de colaboração. Porém, não é especificado e legitimado, em forma de lei, como o regime de colaboração deve ser articulado e desenvolvido por cada ente federado. Somente orienta que a União coordene toda a organização dos sistemas de ensino.

Com base nesse pressuposto, concordamos com Andrade (2012) quando afirma que a municipalização do ensino não pode ser considerada como um processo de repartição das matrículas entre os entes federados, mas uma exigência legal que redefine a organização e redistribui as incumbências de cada esfera para assumi-las, tomando por referência a colaboração.

Portanto, percebemos claramente a influência das políticas públicas educacionais para o processo de municipalização do ensino, norteando a organização dos sistemas municipais de ensino. As políticas mencionadas trazem autonomia aos municípios para definir suas propostas de ensino e, simultaneamente, apresentam inúmeros desafios para a gestão educacional dos municípios brasileiros.

\section{PROCEDIMENTOS METODOLÓGICOS}

Esta investigação tem como base a pesquisa qualitativa, evidenciando o levantamento bibliográfico e a análise documental. Inicialmente, realizamos uma revisão bibliográfica no intuito de encontrar aportes teóricos que discutam a temática e ajudem a subsidiar esta pesquisa, etapa indispensável numa investigação científica. A esse respeito, Minayo (2009) alerta sobre três cuidados essenciais para fazer uma revisão bibliográfica, a qual deve ser "disciplinada, crítica e ampla". A disciplina é necessária para uma prática de pesquisa sistemática que possua critérios claros para a escolha dos textos e autores. Já a criticidade estabelece um diálogo reflexivo entre os estudos e as teorias com o objeto que se pretende investigar. Por fim, a amplitude é necessária, pois o pesquisador precisa apresentar o que é consenso (muito conhecido) sobre o assunto a ser discutido e o que é polêmico (pouco se sabe). 
A revisão bibliográfica foi realizada por meio de leitura e fichamentos dos textos que discutem o federalismo, descentralização, municipalização, gestão educacional e as políticas públicas. Os textos foram selecionados, incluindo artigos de revistas especializadas e atualizadas, livros online ou impressos, mantendo-se vigilante com as fontes. Destacamos os autores como Barroso (2002) e Azevedo (1997) que discorrem sobre políticas públicas e a gestão da educação básica; Akkari (2011) que reflete sobre a internacionalização das políticas educacionais e os seus desafios; Araújo (2010) que discute sobre a relação existente entre federalismo e municipalização, historicizando esse processo no Brasil.

Além disso, destacamos a contribuição da análise documental para a finalização deste estudo. A análise documental será realizada na perspectiva dos documentos impressos, entendendo que as "fontes de papel" são capazes de proporcionar ao pesquisador dados riquíssimos de maneira que, em alguns casos, só se torna possível realizar a investigação a partir de documentos, focalizando nos registros institucionais. Estes são relacionados aos registros escritos pelas instituições governamentais, como projetos de lei, relatórios de órgãos governamentais, atas de reuniões de casas legislativas, atas judiciais e documentos registrados em cartório, entre outros que precedam dos órgãos governamentais (Gil, 1999).

O enfoque metodológico desta pesquisa se dará nos registros (documentos) institucionais escritos: dos documentos oficiais: a Constituição Federal de 1988 e a Lei de Diretrizes e Bases da Educação - LDB 9394/96, que regulamentam a educação brasileira. Compreendemos que a discussão acerca dessa temática se faz pertinente, uma vez que percebemos nas leituras e nas discussões coletivas em sala de aula a necessidade de refletir sobre os desafios que a gestão educacional municipal enfrenta diante do processo de descentralização, provindo pelas políticas públicas.

\section{RESULTADOS E DISCUSSÕES}

4.1 Municipalização: desafios da gestão educacional

O debate acerca da gestão educacional se apresenta de forma mais frequente na atualidade. Com o processo de municipalização, a gestão educacional ganhou novos enfoques, pois a sua organização começou a contar com o apoio de sistemas de ensino federal, estadual e municipal, possibilitando suas ações baseadas em princípio de autonomia e de democracia.

A partir do processo de municipalização, os órgãos federal, estadual e municipal passaram a pensar suas ações direcionadas para o sistema educacional de forma coletiva, socializando e colaborando conjuntamente as ações destinadas para o ensino. Esse processo rompe com uma visão centralizada em um único órgão.

Dessa forma, o processo de descentralização foi fundamental para a concretização da municipalização, o que resultou, assim como argumenta Akkari (2011), em uma das maiores reformas implantadas na educação brasileira.

Sobre isso, corroboramos das ideias de Azevedo quando destaca que:

Nos últimos sete anos têm ocorrido no Brasil uma progressiva municipalização do ensino fundamental, da educação infantil e de jovens e adultos decorrente de 
induções/programas do poder central que assumiu a descentralização como um dos princípios das políticas educativas (Azevedo, 1997, p. 49).

O processo de descentralização proporcionou uma abertura para a municipalização. Nesse sentido, o órgão municipal passou a assumir a responsabilidade de organizar as ações para a educação. Entre essas responsabilidades, umas delas, assim como destaca Mota (2010, p. 07), "coube aos Municípios, de acordo com a LDB; a chamada anual da população com 7 anos para matrícula na escola primária (Art. 29)".

Mediante a isso, a gestão educacional começou a lidar com as novas delegações dos órgãos federais, estaduais e municipais, vindo a se articularem com as demais instâncias que estabelecem as normas, que são exercidas e determinadas no sistema educacional e, por fim, pela oferta educacional disponibilizado pelo setor público e privado.

Dessa forma, compreendemos com base em Akkari (2011), que a descentralização contribuiu fortemente para a municipalização do ensino menos hierárquico administrativo, porém, desencadeou também, menor capacidade de gerir a Educação, haja vista que a descentralização precisa ter um planejamento organizado para que as instituições de ensino, que também recebem as responsabilidades de administrar uma política educacional, possam realizá-la de maneira bem sucedida. Tal fator influencia fortemente na gestão educacional. Nesse sentido, a gestão educacional passou a enfrentar novos desafios desencadeados, sobretudo, por essa nova organização política do ensino.

Um dos desafios a ser enfrentado com o processo da municipalização diz respeito, assim como destaca Barroso (2002), às questões que afetam o domínio das políticas públicas educacionais e da gestão da educação, resultando numa crise geral do modelo de organização e da administração que se apresenta na origem do sistema nacional de ensino.

Nesse sentido, o Estado, na tentativa de superar tal crise, adotou diferentes medidas de caráter político, administrativo e pedagógico, enfatizando que, dentre estas, a que se sobressai é a gestão local da educação que inclui a descentralização municipal (Barroso, 2002).

Barroso (2002) ainda aponta que as políticas educacionais são fortemente caracterizadas pelo voluntarismo governamental, baseada na participação de todos os envolvidos do processo educativo. Para isso, o município e sua administração assume um poder determinante sobre a organização e funcionamento do sistema educativo, através da definição e controle da execução de todo o currículo, da organização administrativa e pedagógica, da formação, nomeação e gestão do pessoal docente, da avaliação dos alunos, bem como, da distribuição dos recursos.

Cabe à gestão educacional o papel de saber lidar e articular de forma organizada e equilibrada o desenvolvimento das ações direcionadas para cada um desses setores, pois, assim como argumenta Barroso (2002), existe um "conflito" entre os atores no que se refere à organização e ao funcionamento dessas ações na escola, afetando a gestão educacional.

Nesse sentido, compreendemos que compete à gestão educacional do município procurar, constantemente, um equilíbrio para que assim possa acontecer um melhor desempenho das ações dos atores envolvidos para o ensino. Desse modo, para integrar o regime de colaboração entre os entes federados, bem como entre os atores envolvidos na gestão educacional, é necessário que os municípios instituam seus sistemas municipais de ensino como já existem nos estados federados e na União, trazendo, também, o desafio da criação de Conselhos Municipais de 
Educação e outras instâncias para envolver a participação da sociedade civil nas decisões educacionais. Torna-se indispensável maior comprometimento dos dirigentes municipais na sua filosofia de ação e nas diretrizes estabelecidas para a política educacional.

Andrade (2012) enfatiza, com base em estudos, algumas lacunas existentes com o processo de municipalização, resultando em mais desafios para o bom funcionamento da gestão educacional. Entre esses desafios ganha destaque a carência no que se refere à capacidade inventiva e autônoma dos municípios, que acaba refletindo no processo político de descentralização.

Outro fator relevante apontado por Andrade (2012), baseado nos estudo de Salomão e Araújo, diz respeito às políticas de municipalização da educação que não foram pensadas como mecanismos de superação das desigualdades educacionais apontadas pelo Estado, como também as políticas de financiamento, que não são capazes de fornecer o equilíbrio necessário entre os diferentes governos locais para garantir as condições da qualidade para educação

Por fim, para que ocorra um funcionamento integrado e mais eficaz da gestão educacional se faz necessário o envolvimento dos pais e os demais segmentos dessa comunidade nas atividades educativas, ou seja, uma 'co-responsabilização' ${ }^{2}$ na sua gestão, construindo o processo de democratização do Estado e da sociedade com o exercício da cidadania para a construção da gestão municipal da educação e políticas públicas educacionais.

\section{CONSIDERAÇÕES FINAIS}

Este trabalho nos possibilitou refletir sobre as influências das políticas públicas educacionais no processo de municipalização, bem como conhecer alguns desafios enfrentados pela gestão educacional. Dessa forma, foi possível inferir, à luz dos autores, que o processo de municipalização trouxe desafios, mas também ganhos para a gestão da educação, uma vez que a discussão surge com base nos princípios de autonomia, democracia e descentralização no cotidiano escolar. Além disso, proporcionou a oportunidade dos municípios instituírem seus sistemas municipais de ensino, como já existem nos estados federados e na união.

Os desafios a serem enfrentados são: a criação de Conselhos Municipais de Educação, bem como outras instâncias para envolver a participação da sociedade civil na formulação dos projetos políticos pedagógicos e planos municipais de educação. Nesses termos, é necessário maior comprometimento dos dirigentes municipais na sua filosofia de ação e as diretrizes estabelecidas para a política educacional, a partir das incumbências que foram atribuídas para os municípios.

Destacamos ainda o desafio de sistematizar a oferta da educação infantil e o ensino fundamental, o que requer melhoria na estrutura física, capacitação profissional e recursos financeiros. Assim, visando a superaração desses desafios, a União criou programas para auxílio financeiro, desenvolvendo um regime de colaboração entre municípios, estados e o Distrito Federal.

No que diz respeito às mudanças desencadeadas na gestão da educação, a partir do processo de municipalização, percebemos que os gestores municipais necessitam colocar em prática na sua administração o processo de descentralização para possibilitar a abertura para a

${ }^{2}$ Termo utilizado por Barroso (2002).

HOLOS, Ano 33, Vol. 03 
participação social, por meio dos conselhos escolares municipais, legitimados pelas políticas públicas educacionais, colaborando na organização dos seus sistemas de ensino. Ressaltamos ainda a responsabilidade de promover a construção de suas próprias políticas educacionais, usando da autonomia da gestão local.

Podemos concluir que a maior mudança permitida por esse processo de municipalização foi a abertura para os gestores municipais criarem suas propostas de ensino, com a participação social e suas políticas educacionais, sempre tomando por base as orientações nacionais.

\section{REFERÊNCIAS}

Akkari, Abdeljalil. (2011). Internacionalização das políticas educacionais: transformações e desafios. Petrópolis: Vozes.

Andrade, Bonifácio José Tamm de. (2012). Federação. In: Dicionário de Política Pública no Brasil. Universidade do Estado de Minas Gerais (UEMG). Publicado em 2012 (online) no site <http://www.ebc.com.br/cidadania/2013/02/primeiro-dicionario-sobre-politicas-publicas-nobrasil>.

Andrade, Edson Francisco de. (2012). Poder Local e Regime de Colaboração na gestão da política educacional no Brasil. In: Sistemas municipais de educação: impactos na gestão educacional no âmbito do poder local. Campinas. São Paulo: Mercado de Letras.

Araújo, Gilda Cardoso de. (2010). A relação entre federalismo e municipalização: desafios para a construção do sistema nacional e articulado de educação no Brasil. Revista Educação e Pesquisa. São Paulo, 36 (1), 389 -402.

Azevedo, Janete Maria Lins de. (1997). A educação como política pública. Campinas- SP.: Autores Associados.

Barroso, João. (2002). Gestão local da educação: entre o Estado e o mercado, a responsabilização coletiva In: MACHADO, Lourdes Marcelino; FERREIRA, Naura Syria Carapeto (Org.). Política e Gestão da educação: dois olhares. Rio de Janeiro: DP\&A.

Batista, Karla da Silva Costa. (2012). Município. In: Dicionário de Política Pública no Brasil. (online). Universidade do Estado de Minas Gerais (UEMG). Disponível em:

<http://www.ebc.com.br/cidadania/2013/02/primeiro-dicionario-sobre-politicas-publicas-nobrasil>.

Brasil. (1988). Constituição da República Federativa do Brasil. Brasília - DF: Senado, 1988.

Brasil. (1996). Lei n. 9.394, de 20 de dezembro de 1996. Lei de Diretrizes e Bases da Educação. Brasília - DF.

Castro, Alda Maria Duarte Araújo, Lauande, Maria de Fátima Ribeiro Franco. (2009). A descentralização como componente da gestão educacional. In: Associação Nacional de Política e Administração da Educação - ANPAE, 8 , Vitória - ES. 
Espinosa, Roberto Moreno. (2012). Descentralização. In: Dicionário de Política Pública no Brasil. Universidade do Estado de Minas Gerais (UEMG). Disponível em:

<http://www.ebc.com.br/cidadania/2013/02/primeiro-dicionario-sobre-politicas-publicas-nobrasil>.

Filippim, Eliane Salete, Abrucio, Fernando Luiz. (2010). Quando Descentralizar é Concentração de Poder: o papel do Governo Estadual na Experiência Catarinense. Revista de Administração Contemporânea. Curitiba, 14 (2), 212-228.

Gil, Antônio Carlos. (1999). Métodos e Técnicas de Pesquisa Social. 5. ed. São Paulo: Atlas.

Melo Filho, Luiz Gonzaga Pereira de. (2013). O Município como Ente Federativo. Conteúdo Jurídico, Brasília-DF. Disponível em: <http://www.conteudojuridico.com.br/?artigos\&ver=2.41832>.

Minayo, Maria Cecília de Souza (Org.). (2009). Pesquisa Social: teoria, método e criatividade. 28. ed. Petropólis: Vozes.

Mota, Ademar Benedito Ribeiro da. (2010). A história da municipalização do ensino no Brasil. Disponível em:

<http://www.histedbr.fe.unicamp.br/acer_histedbr/jornada/jornada7/_GT2\%20PDF/A\%20HIST\% D3RIA\%20DA\%20MUNICIPALIZA\%C7\%C30\%20DO\%20ENSINO\%20NO\%20BRASIL.pdf>. 